\title{
CONCURRENT VARICELLA WITH HERPES ZOSTER IN A CHILD.
}

\author{
Dr. Sundeep Chowdhry ${ }^{1}$, Dr. Prashansa Jaiswal ${ }^{2}$,Dr. Tapan Kumar Dhali ${ }^{3}$, Dr. Akhilesh Shukla ${ }^{4}$
}

\begin{abstract}
A 3 year old girl presented with a two- day history of multiple fluid filled lesions on buttocks and back of left thigh. As informed by the child's mother, she had fever 4 days back and was irritable with pain and discomfort on back of the left thigh. The pain was episodic and radiated from buttocks to the leg. On examination, multiple fluid filled lesions of various sizes with surrounding erythema were present involving the S1, S2, S3 dermatomes extending from buttock to the sole sparing few areas in between the vesicles. On further examination of whole body, there were multiple discrete fluid filled lesions on erythematous base ranging from 0.1 to $0.3 \mathrm{~mm}$ diameter in size on chest, abdomen and back. Multinucleated giant cells with acantholytic cells were found in Tzank smears. Diagnosis of concurrent varicella with herpes zoster was made.
\end{abstract}

KEYWORDS: Concurrent, Varicella, Herpes Zoster

1. Assistant Professor, ESIPGIMSR, Basaidarapur, New Delhi

2. PG Student, ESIPGIMSR, Basaidarapur, New Delhi

3. Associate Professor, ESIPGIMSR, Basaidarapur, New Delhi

4. PG Student, ESIPGIMSR, Basaidarapur, New Delhi

\author{
For Correspondence \\ Dr. Tapan Kumar Dhali \\ Associate Professor, MD, DVL, ESIPGIMSR, \\ Basaisarapur, New Delhi \\ Address: C 105, Tagore Garden Extension, \\ New Delhi 110027 \\ Email:tapan99@gmail.com
}




\section{INTRODUCTION:}

Varicella (chickenpox), a common contagious disease of childhood, is caused by the varicella zoster virus (VZV). ${ }^{1} \mathrm{VZV}$ (DNA virus) belongs to alpha herpes virus group and establishes latency in the cells of the dorsal root ganglia after an episode of primary infection. The etiology of varicella and herpes zoster was first reported by von Bo'kay in 1888 from the observation that susceptible children often developed varicella after exposure to adults with herpes zoster. ${ }^{1,2,3} \mathrm{VZV}$ was isolated from vesicular fluid of both chickenpox and zoster lesions in cell culture by Thomas Weller in $1954 .{ }^{4}$ Once the chickenpox resolved, the virus settles down within the neurons of cranial nerves and dorsal root ganglia throughout the lifetime of the host. ${ }^{5,6}$ We report this case because the two conditions rarely occur concurrently in the same individual.

\section{CASE REPORT:}

A 3 year old girl presented with two days history of multiple fluid filled lesions on buttocks and back of left thigh. As informed by the child's mother, she had fever 4 days back and was irritable with pain and discomfort on back of the left thigh. The pain was episodic in nature and radiated from the buttocks to the leg. On examination, multiple fluid filled lesions of various sizes with surrounding erythema were present on the skin involving S1, S2, S3 dermatomes and these extended from buttock to the sole with sparing of few areas in between them. These eruptions were arranged in groups and varied from $0.1 \mathrm{~mm}$ to $0.3 \mathrm{~mm}$ in size. (Figure 1).

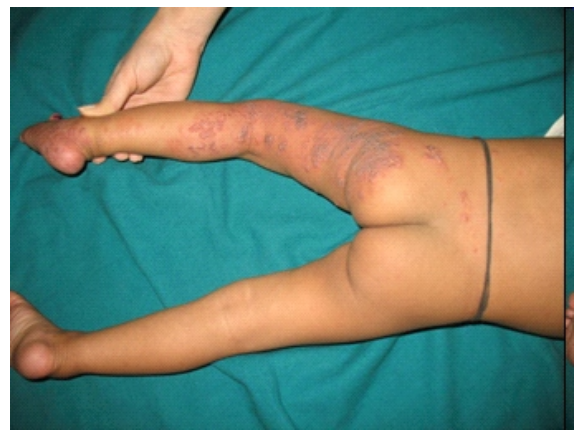

Figure 1.Grouped vesicles on S1, S2, S3 dermatome.

On further examination of the whole body, there were multiple discrete fluid filled lesions on erythematous base ranging from 0.1 to $0.3 \mathrm{~mm}$ diameter in size on chest, abdomen and back (Figure 2). On further probing, mother of the child revealed that both fluid filled lesions over body and leg appeared simultaneously. No history of similar lesions was there in the past. Tzanck smear from lesions over body and leg was

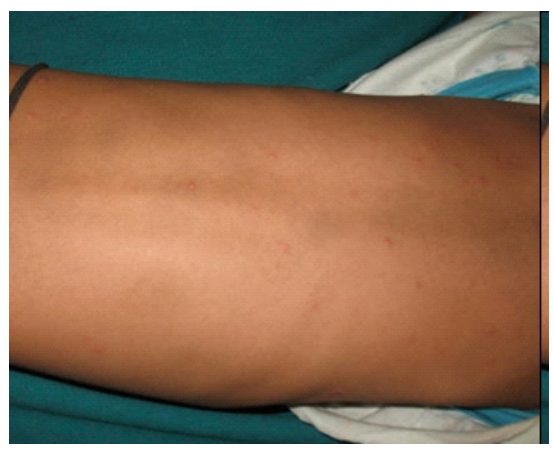

Figure 2. Discrete vesicles on back

examined and subjected for both gram stain and geimsa stain. Gram stain showed lymphocytes and neutrophils. Multinucleated giant cells were found in tzank smear (Figure $3)$.

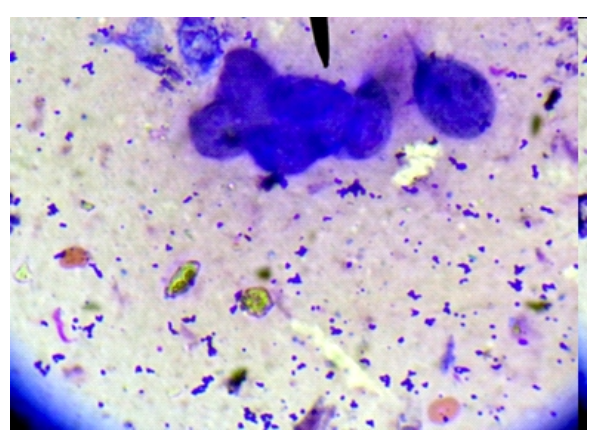

Figure 3. Tzank smear showing multinucleated cells

Hemogram was within normal limits. Serology for antibody titre of varicella was positive $(130 \mathrm{mIU} / \mathrm{ml})$. HIV serology was negative in both child and the mother. The child was treated within two hours of diagnosis with acyclovir oral suspension in dose of $300 \mathrm{mg}$ five times a day for a period of seven days. Syrup paracetamol (as per body weight), syrup multivitamin and mupirocin cream were prescribed in addition to the above. The mother was advised to isolate the child from other family members and contacts for about 7-10 days. The child was reviewed after 3 days by which the lesions subsided. The patient was again reviewed on the 7 th day and by the tenth day the lesions on the trunk healed with hypopigmentation and lesions on thigh healed with both hypo and hyperpigmentation.

\section{DISCUSSION:}

VZV causes a wide range of disorders including chickenpox in childhood and shingles in elderly. ${ }^{5}$ Patients are usually infectious to others from about 2 days before to 5 days after the 
onset of the rash. A decline in host immunity, usually in elderly and immunocompromised individuals, results in reactivation of the virus from latency. This is followed by the spread of reactivated virus to the skin through axons, causing a radicular pain and rash in the form of vesicles on an erythematous base with characteristic dermatomal distribution. ${ }^{5,6}$ Since VZV is latent in numerous sensory ganglia, herpetic vesicles can occur anywhere on the body, commonly in thoracic, trigeminal and multiple dorsal root ganglia. ${ }^{6}$

Thus, varicella results from the primary VZV infection, whereas herpes zoster (shingles) is the result of reactivation. ${ }^{1,2,8}$ There is a certain lag period between the primary varicella infection and herpes zoster, that is why varicella usually occurs in children and zoster occurs in adult. Primary varicella infection usually results in lifetime immunity, and second episodes of varicella are uncommon, but they may occur. Though both herpes zoster and varicella are produced by the same virus, in herpes zoster the eruption follows the distribution of the cutaneous nerves and the virus is said to be neurotropic, whereas in varicella there is no such distribution and it is said to be dermatropic. ${ }^{10}$ Strangely enough the two conditions rarely occur in the same individual that too in a child, and only six cases have been reported in the literature. ${ }^{9-14}$ Though the core existence of varicella and herpes zoster has been reported in the past, their coexistence is still uncommon, and in our case the young age of the child is significant. Also a detailed workup is preferred in such cases.

\section{CONCLUSION:}

In view of the fact that both conditions are probably produced by the same virus, the reason why on some occasions the virus assumes neurotropic qualities and in others dermatropic qualities is not clear and necessitates further analysis.

\section{REFERENCES:}

1. CDC. 2005. Varicella. In: Epidemiology and Prevention of Vaccine-Preventable Diseases (Atkinson W, ed). Atlanta, GA:Centers for Disease Control and Prevention, 159175.

2. Arvin A. Varicella-zoster virus. Clin Microbiol Rev 1996 9(3):361381.

3.Von Bo'kay J. Uëber den aëtiologischen Zusammenhang der Varizellen mit gewissen Fällen von Herpes Zoster [in German]. Wien Klin Wochenschr 1909 22:13231326.

4. Thomas.H.Weller, Hellen. M. Witton and E. John Bell, "The Etiologic agents of Varicella and Herpes Zoster:Isolation:
Propagation and Cultural Characteristics In Vitro".Journal of ExperimentalMedicine 108,No.6(1958):843-68

5. Kleinschmidt-DeMasters BK, Gilden DH: Varicella-zoster virus infections of the nervous system. Arch Pathol Lab Med 2001,125:770-780.

6. Gilden DH, Mahalingam R, Cohrs RJ, Tyler KL: Herpesvirus infections of the nervous system. Nat Clin Pract Neurol 2007,3:82-94

7. Zerboni L, Ku C, Jones CD, Zehnder JL, Arvin AM: Varicellazoster virus infection of human dorsal root ganglia in vivo. Proc Natl Acad Sci USA 2005, 102:6490-6495.

8. Jumaan A, Hughes H, Schmid S, Galil K, Plott K, Zimmerman L, et al. 2002. Varicella. In: Manual for the Surveillance of VaccinePreventable Diseases (Wharton M, Hughes H, Reilly M, eds). Atlanta, GA:Centers for Disease Control and Prevention, 1121.

9. Muller BK, Gomes WJ. Concorrent Herpes zoster and Varicella.British medical journal.1965 April 24; 1 (5442):11271128.

10. Garrett, F. E. Amer. 7. Ophthal., 1958, 46, 741.

11. Melnotte, P. A., and Foliguet, J. M., Rev. mid.Nancy, 1960, 85, 38.

12. McShane, C. B., E. Afr. med. 7., 1961, 38, 466.

13. Behera, U. C., and Misra, M. C., 7. Indian med.Ass., 1962, 38, 345 .

14. Fry, A., Practitioner, 1964, 192, 673. 